\title{
Interactions of self-interstitials with interstitial carbon-interstitial oxygen center in irradiated silicon: an infrared absorption study
}

\author{
L.I. Murin ${ }^{1, a}$, B.G. Svensson ${ }^{2, b}$, V.P. Markevich ${ }^{3, c}$, A.R. Peaker ${ }^{3, d}$ \\ ${ }^{1}$ Scientific-Practical Materials Research Center of NAS of Belarus, Minsk 220072, Belarus \\ ${ }^{2}$ Oslo University, Department of Physics/Centre for Materials Science and Nanotechnology, N- \\ 0318 Oslo, Norway \\ ${ }^{3}$ The University of Manchester, Manchester M13 9PL, United Kingdom \\ amurin@ifttp.bas-net.by, bb.g.svensson@fys.uio.no, \\ cv.markevich@manchester.ac.uk, dpeaker@manchester.ac.uk
}

Keywords: Silicon, defects, $\mathrm{I}_{n} \mathrm{C}_{i} \mathrm{O}_{i}$ complexes, IR absorption, vibrational modes.

\begin{abstract}
The evolution of radiation-induced carbon-oxygen related defects with the fluence of $\mathrm{MeV}$ electrons and upon subsequent isochronal annealing $\left(75-350{ }^{\circ} \mathrm{C}\right)$ in $\mathrm{Si}$ crystals with different carbon and oxygen content has been studied by means of Local Vibrational Mode (LVM) spectroscopy. In particular, the generation kinetics of the bands at 998 and $991 \mathrm{~cm}^{-1}$ is considered and additional arguments supporting their previous assignment to the $\mathrm{I}_{2} \mathrm{C}_{\mathrm{i}} \mathrm{O}_{\mathrm{i}}$ and $\mathrm{I}_{3} \mathrm{C}_{\mathrm{i}} \mathrm{O}_{\mathrm{i}}$ complexes are found. An annealing behaviour of the LVMs related to the $\mathrm{C} 4\left(\mathrm{IC}_{\mathrm{i}} \mathrm{O}_{\mathrm{i}}\right)$ defect has been studied in the various Si crystals irradiated with different particles. In all the samples studied the bands at 940 and $1024 \mathrm{~cm}^{-1}$ are found to disappear at about $200{ }^{\circ} \mathrm{C}$ while three new LVM bands, at $724 \mathrm{~cm}^{-1}$ (Orelated) and at 952 and $973 \mathrm{~cm}^{-1}$ (both C-related) are emerging. Further increase in annealing temperature up to $250-275^{\circ} \mathrm{C}$ results in a transformation of the latter bands into another set of LVM bands at $969 \mathrm{~cm}^{-1}$ (O-related) and at 951 and $977 \mathrm{~cm}^{-1}$ (both C-related). These bands disappear upon annealing in the temperature range $300-325^{\circ} \mathrm{C}$. The ratios of all the bands intensities as well as their transformation rates do not depend on the oxygen and carbon content in the Si samples nor on the kind of irradiation (2.5 and $10 \mathrm{MeV}$ electrons, fast neutrons) and irradiation doses. These facts confirm our previous conclusion that all the above-mentioned LVMs arise from the $\mathrm{C} 4$ defect being in different configurations $\left(\mathrm{IC}_{\mathrm{i}} \mathrm{O}_{\mathrm{i}}, \mathrm{IC}_{\mathrm{i}} \mathrm{O}_{\mathrm{i}}{ }^{*}\right.$, and $\left.\mathrm{IC}_{\mathrm{i}} \mathrm{O}_{\mathrm{i}}^{* *}\right)$.
\end{abstract}

\section{Introduction}

Along with oxygen, carbon is one of the most abundant impurities in Si crystals. In Czochralski grown silicon $(\mathrm{Cz}-\mathrm{Si})$ it is present normally in concentration of about $10^{15}-10^{16} \mathrm{~cm}^{-3}$ and sometimes higher. The presence of carbon can affect significantly many of the oxygen-related defect reactions that occur upon heat-treatments at elevated temperatures or irradiations with high-energy particles [1-3]. In the latter case a major role of carbon is the trapping of the Si self-interstitials. Interstitial carbon atoms $\left(\mathrm{C}_{\mathrm{i}}\right)$, generated via the Watkins displacement mechanism, are mobile at room temperatures and can interact with other defects and impurities. In $\mathrm{Cz}-\mathrm{Si}$ the main sink for diffusing $\mathrm{C}_{\mathrm{i}}$ is interstitial oxygen $\left(\mathrm{O}_{\mathrm{i}}\right)$ and as a result the $\mathrm{C}_{\mathrm{i}} \mathrm{O}_{\mathrm{i}}$ complex $(\mathrm{C} 3$ defect $)$ [4-7] is generated as one of the dominant radiation-induced centers. The $\mathrm{C}_{\mathrm{i}} \mathrm{O}_{\mathrm{i}}$ defect, in turn, appears to be a very effective trap for the $\mathrm{Si}$ self-interstitial atoms (I) and at doses when the $\mathrm{C}_{\mathrm{i}} \mathrm{O}_{\mathrm{i}}$ concentration becomes comparable with that of $\mathrm{C}_{\mathrm{s}}$ the so-called $\mathrm{C} 4$ defect $\left(\mathrm{IC}_{\mathrm{i}} \mathrm{O}_{\mathrm{i}}\right)$ is generated efficiently. This defect has been detected only in infrared (IR) absorption studies [4, 5]. It gives rise to two main bands located at low temperature at about 940 and $1024 \mathrm{~cm}^{-1}$ (936 and $1020 \mathrm{~cm}^{-1}$ at room temperature). The first band is carbon related while the second one is mainly oxygen related [7, 8].

Upon further increase in the irradiation dose the $\mathrm{C} 4$ defect appears to be a trap for the $\mathrm{Si}$ interstitial atoms as well and a successive formation of $\mathrm{I}_{n} \mathrm{O}_{i} \mathrm{C}_{i}(n \geq 2)$ centers is expected [5]. It was suggested by us earlier [7,9] that the absorption bands at 998 and $991 \mathrm{~cm}^{-1}$ are related to the $\mathrm{I}_{2} \mathrm{C}_{\mathrm{i}} \mathrm{O}_{\mathrm{i}}$ 
and $\mathrm{I}_{3} \mathrm{C}_{\mathrm{i}} \mathrm{O}_{\mathrm{i}}$ defects, respectively. However, in the references $[10,11]$ these vibrational bands were assigned to the $\mathrm{IC}_{\mathrm{i}} \mathrm{C}_{\mathrm{s}}$ complex. In present work the generation kinetics of the bands at 998 and 991 $\mathrm{cm}^{-1}$ has been studied and further arguments supporting their previous assignment to the $\mathrm{I}_{2} \mathrm{C}_{\mathrm{i}} \mathrm{O}_{\mathrm{i}}$ and $\mathrm{I}_{3} \mathrm{C}_{\mathrm{i}} \mathrm{O}_{\mathrm{i}}$ complexes have been found.

Another problem discussed in this paper is related to configurational transformations of the $\mathrm{C} 4$ defect upon isochronal annealing [9]. There is no consensus between experimental data [9] and the results of ab-initio modeling [12]. We will present some additional results on the $\mathrm{C} 4$ annealing behavior, which confirm our previous assignments.

\section{Experimental details}

The samples used in this investigation were prepared from n-type Cz-Si crystals $(\rho=10-50 \Omega$-cm, $\left.\left.\left[\mathrm{O}_{\mathrm{i}}\right]=(0.8-1.3) \times 10^{18} \mathrm{~cm}^{-3}\right),\left[\mathrm{C}_{\mathrm{s}}\right]=(0.5-3.0) \times 10^{17} \mathrm{~cm}^{-3}\right)$. The concentrations of $\mathrm{O}_{\mathrm{i}}$ and $\mathrm{C}_{\mathrm{s}}$ were determined from measurements of intensities of absorption bands at 1107 and $605 \mathrm{~cm}^{-1}$ using the calibration coefficients $3.14 \times 10^{17}$ and $0.94 \times 10^{17} \mathrm{~cm}^{-2}$, respectively [1]. The samples were polished to an optical surface on two sides and the dimensions were $10 \times 5 \times 3 \mathrm{~mm}^{3}$.

Irradiation with 2.5 and $10 \mathrm{MeV}$ electrons was performed at room temperature (RT) by different fluencies in the range $1 \cdot 10^{16}-2 \cdot 10^{18} \mathrm{~cm}^{-2}$ and the samples were kept at RT for several months before measurements. A few samples were irradiated with $5 \mathrm{MeV}$ neutrons. Isochronal annealing studies have been carried out in the temperature range $75-350{ }^{\circ} \mathrm{C}$ in $25{ }^{\circ} \mathrm{C}$ steps for 30 min at each temperature. IR absorption analysis was carried out using a Bruker IFS 113v spectrometer. A spectral resolution of 0.5 or $1.0 \mathrm{~cm}^{-1}$ was used and the samples were measured at 20 and $300 \mathrm{~K}$.

\section{Experimental results}

$\mathrm{I}_{2} \mathrm{C}_{\mathbf{i}} \mathrm{O}_{\mathbf{i}}$ and $\mathrm{I}_{3} \mathrm{C}_{\mathbf{i}} \mathrm{O}_{\mathbf{i}}$ defects. Figure 1 shows the development of the IR absorption spectra in the wavenumber range $800-1040 \mathrm{~cm}^{-1}$ with accumulated dose of $2.5 \mathrm{MeV}$ electrons for a $\mathrm{Cz}-\mathrm{Si}$ sample with an intermediate carbon concentration $\left(\left[\mathrm{C}_{\mathrm{s}}\right]=5 \times 10^{16} \mathrm{~cm}^{-3}\right)$. Along with the dominant and well known absorption band at $830 \mathrm{~cm}^{-1}$ related to vacancy-oxygen complex (A-center) several weaker vibrational bands positioned at $862,936,988,994$ and $1020 \mathrm{~cm}^{-1}$ are seen in the spectra. All of the latter bands are associated with the radiation-induced centers involving carbon since none of them could be observed in the absorption spectra of $\mathrm{Cz}-\mathrm{Si}$ with low carbon content $\left(\left[\mathrm{C}_{\mathrm{s}}\right]<10^{15} \mathrm{~cm}^{-3}\right)$ [13]. Apparently, the well known band at $862 \mathrm{~cm}^{-1}$ is related to $\mathrm{C}_{\mathrm{i}} \mathrm{O}_{\mathrm{i}}$ defect [1, 4-7], the bands at 936 and $1020 \mathrm{~cm}^{-1}$ are due to $\mathrm{IC}_{\mathrm{i}} \mathrm{O}_{\mathrm{i}}[1,5,7]$. Most likely, the absorption bands at 998 and $991 \mathrm{~cm}^{-1}$ are associated with $\mathrm{I}_{2} \mathrm{C}_{\mathrm{i}} \mathrm{O}_{\mathrm{i}}$ and $\mathrm{I}_{3} \mathrm{C}_{\mathrm{i}} \mathrm{O}_{\mathrm{i}}$ defects, respectively [7].

Evidently, formation of all the abovementioned centres should occur via the following sequential reactions [5]:

$$
\begin{gathered}
\mathrm{I}+\mathrm{C}_{\mathrm{s}} \rightarrow \mathrm{C}_{\mathrm{i}} \\
\mathrm{C}_{\mathrm{i}}+\mathrm{O}_{\mathrm{i}} \rightarrow \mathrm{C}_{\mathrm{i}} \mathrm{O}_{\mathrm{i}} \\
\mathrm{I}+\mathrm{C}_{\mathrm{i}} \mathrm{O}_{\mathrm{i}} \rightarrow \mathrm{IC}_{\mathrm{i}} \mathrm{O}_{\mathrm{i}} \\
\mathrm{I}+\mathrm{IC}_{\mathrm{i}} \mathrm{O}_{\mathrm{i}} \rightarrow \mathrm{I}_{2} \mathrm{C}_{\mathrm{i}} \mathrm{O}_{\mathrm{i}} \\
\mathrm{I}+\mathrm{I}_{2} \mathrm{C}_{\mathrm{i}} \mathrm{O}_{\mathrm{i}} \rightarrow \mathrm{I}_{3} \mathrm{C}_{\mathrm{i}} \mathrm{O}_{\mathrm{i}} .
\end{gathered}
$$

Figure 2 shows the generation kinetics of the corresponding centers studied. An analysis of the data obtained supports the previously suggested mechanism of the successive formation of the defects giving rise to the bands at 994 and $988 \mathrm{~cm}^{-1}$ in accordance with the above given reaction scheme.

A strong evidence that the centers responsible for the bands at 988 and $994 \mathrm{~cm}^{-1}$ (991 and 998 $\mathrm{cm}^{-1}$ at low temperatures) involve an oxygen atom has been presented in Ref. 7 . In that study a few samples were enriched with ${ }^{18} \mathrm{O}$ oxygen isotope and a clear oxygen isotopic shift was observed for these bands (from 991 and $998 \mathrm{~cm}^{-1}$ in ${ }^{16} \mathrm{O}$-doped Si to 948 and $954 \mathrm{~cm}^{-1}$ in ${ }^{18} \mathrm{O}$-doped Si). So, most 

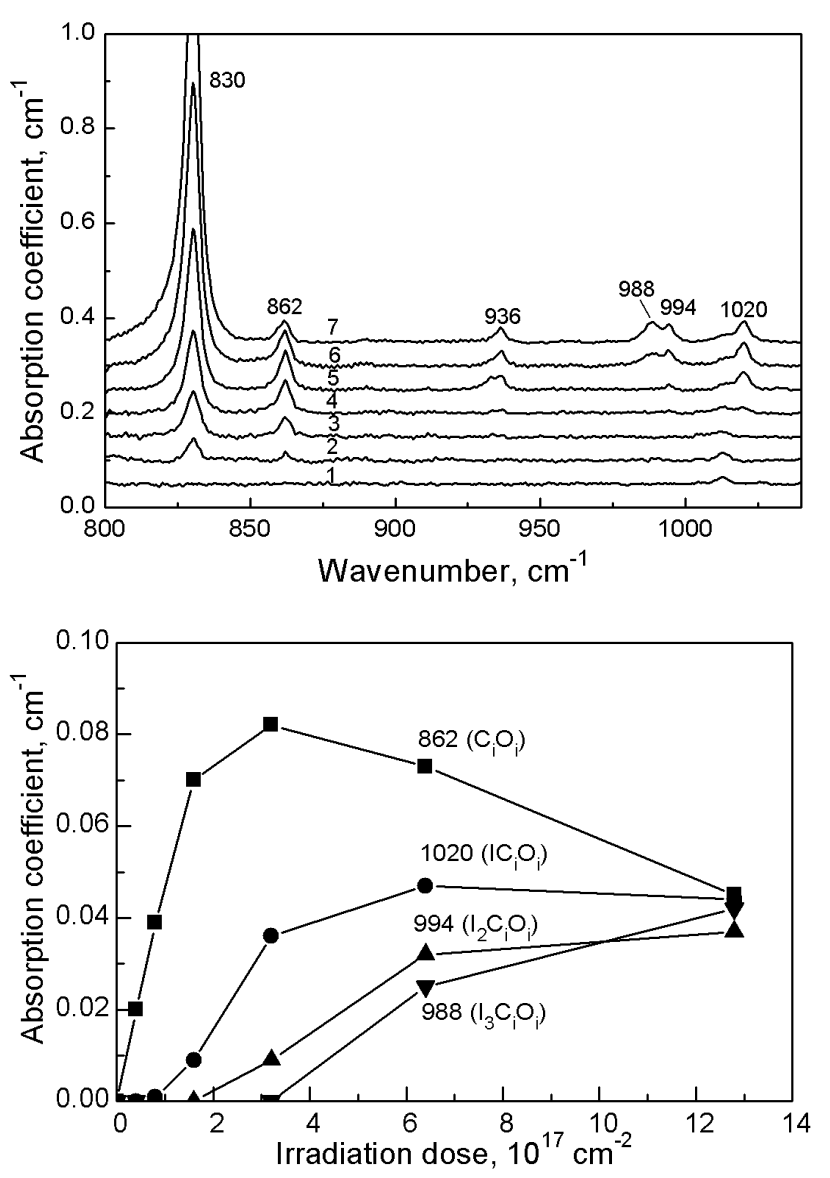

Fig. 1. Fragments of absorption spectra measured at $300 \mathrm{~K}$ for a $\mathrm{Cz}$ Si sample $\left(\left[\mathrm{O}_{\mathrm{i}}\right]=1.0 \times 10^{18},\left[\mathrm{C}_{\mathrm{s}}\right]\right.$ $\left.=5 \times 10^{16},[\mathrm{P}]=1 \times 10^{14} \mathrm{~cm}^{-3}\right)$, as-grown (1) and irradiated at room temperatures with the following accumulate doses of $2.5 \mathrm{MeV}$ electrons: (2) $4 \times 10^{16}$, (3) $8 \times 10^{16}$, (4) $1.6 \times 10^{17}$, (5) $3.2 \times 10^{17}$, (6) $6.4 \times 10^{17}$, and $(7) 1.28 \times 10^{18} \mathrm{~cm}^{-2}$.

Fig. 2. Generation kinetics of $\mathrm{C}_{\mathrm{i}} \mathrm{O}_{\mathrm{i}}$ and $\mathrm{I}_{\mathrm{n}} \mathrm{C}_{\mathrm{i}} \mathrm{O}_{\mathrm{i}}$ defects upon electron irradiation at room temperature (see Fig 1).

likely the bands at 998 and $991 \mathrm{~cm}^{-1}$ are related to oxygen vibrations in the $\mathrm{I}_{2} \mathrm{C}_{\mathrm{i}} \mathrm{O}_{\mathrm{i}}$ and $\mathrm{I}_{3} \mathrm{C}_{\mathrm{i}} \mathrm{O}_{\mathrm{i}}$ defects, respectively. Unfortunately, no corresponding $\mathrm{C}_{\mathrm{i}}$-related LVMs have been detected yet. Perhaps, their intensity is very low, as it does occur for the LVMs of some other carbon involving centres [1].

Isochronal annealing studies carried out by us have shown that the $\mathrm{I}_{2} \mathrm{C}_{\mathrm{i}} \mathrm{O}_{\mathrm{i}}$ and $\mathrm{I}_{3} \mathrm{C}_{\mathrm{i}} \mathrm{O}_{\mathrm{i}}$ defects possess slightly different thermal stabilities: $\mathrm{I}_{2} \mathrm{C}_{\mathrm{i}} \mathrm{O}_{\mathrm{i}}$ is stable up to $400{ }^{\circ} \mathrm{C}$ while $\mathrm{I}_{3} \mathrm{C}_{\mathrm{i}} \mathrm{O}_{\mathrm{i}}$ anneals out at about $300{ }^{\circ} \mathrm{C}$ (see also figures in the next subsection).

$\mathrm{IC}_{\mathbf{i}} \mathrm{O}_{\mathbf{i}}, \mathrm{IC}_{\mathbf{i}} \mathrm{O}_{\mathbf{i}}{ }^{*}$, and $\mathrm{IC}_{\mathbf{i}} \mathrm{O}_{\mathbf{i}}{ }^{* *}$ defects. A complicated annealing behavior of the LVMs related to the $\mathrm{C} 4\left(\mathrm{IC}_{\mathrm{i}} \mathrm{O}_{\mathrm{i}}\right)$ defect has been revealed [9]. At about $200{ }^{\circ} \mathrm{C}$ the bands at 940 and $1024 \mathrm{~cm}^{-1}$ are transformed into 3 new LVM bands at $724 \mathrm{~cm}^{-1}$ (O-related) and at 952 and $973 \mathrm{~cm}^{-1}$ (both Crelated). Further increase in annealing temperature up to $250-275{ }^{\circ} \mathrm{C}$ results in a transformation of the latter bands into a new set of LVM bands at $969 \mathrm{~cm}^{-1}$ (O-related) and at 951 and $977 \mathrm{~cm}^{-1}$ (both C-related). These bands disappear at about $300-325^{\circ} \mathrm{C}$. It has been argued that all the abovementioned LVMs arise from the $\mathrm{C} 4$ defect being in different configurations $\left(\mathrm{IC}_{\mathrm{i}} \mathrm{O}_{\mathrm{i}}, \mathrm{IC}_{\mathrm{i}} \mathrm{O}_{\mathrm{i}}{ }^{*}\right.$, and $\mathrm{IC}_{\mathrm{i}} \mathrm{O}_{\mathrm{i}}{ }^{* *}$, respectively). However, this conclusion has been questioned later [11, 12]. LVMs calculated for the (meta)stable $\mathrm{IC}_{\mathrm{i}} \mathrm{O}_{\mathrm{i}}{ }^{*}$ and $\mathrm{IC}_{\mathrm{i}} \mathrm{O}_{\mathrm{i}}{ }^{* *}$ structures found in an ab-initio study have not matched the wavenumbers of the absorption lines assigned by us to the corresponding defects [12]. Another reason is an absence of the $\mathrm{IC}_{\mathrm{i}} \mathrm{O}_{\mathrm{i}}{ }^{*} \mathrm{LVMs}$ in the IR absorption spectra measured at RT temperature $[11,14,15]$. To solve this puzzle we measured IR spectra at different temperatures in the range $20-300 \mathrm{~K}$ for a Cz-Si sample containing $\mathrm{IC}_{\mathrm{i}} \mathrm{O}_{\mathrm{i}}$ defect after annealing at $200{ }^{\circ} \mathrm{C}$.

Fig. 3 shows evolution of the spectra with the measurement temperature. The vibrational lines assigned to ICiOi* are clearly observed in the spectra measured at $20 \mathrm{~K}$ and $80 \mathrm{~K}$, but they are not observable at room temperature at all. The origin of this phenomenon is not clear and requires a further investigation. 


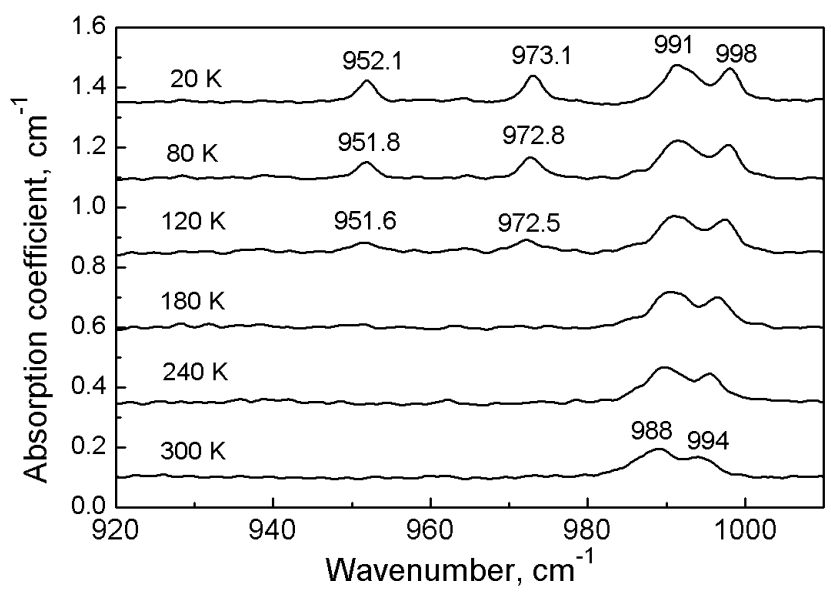

Fig. 3. Development of the absorption spectra in the wavenumber range $920-1010 \mathrm{~cm}^{-1}$ with the measurement temperature for an $\mathrm{n}-\mathrm{CZ}-\mathrm{Si}$ sample irradiated with $2.5 \mathrm{MeV}$ electrons and annealed at $200{ }^{\circ} \mathrm{C}$ for 30 minutes.

Besides, we have carried out annealing studies of the $\mathrm{IC}_{\mathrm{i}} \mathrm{O}_{\mathrm{i}}$ bands in the $\mathrm{Si}$ crystals with different oxygen and carbon content and irradiated with different particles $(2.5 \mathrm{MeV}$ and $10 \mathrm{MeV}$ electrons and $5 \mathrm{MeV}$ fast neutrons) for different doses. Figures 4-6 show the development of the IR absorption spectra with the annealing temperature in some of the samples studied.
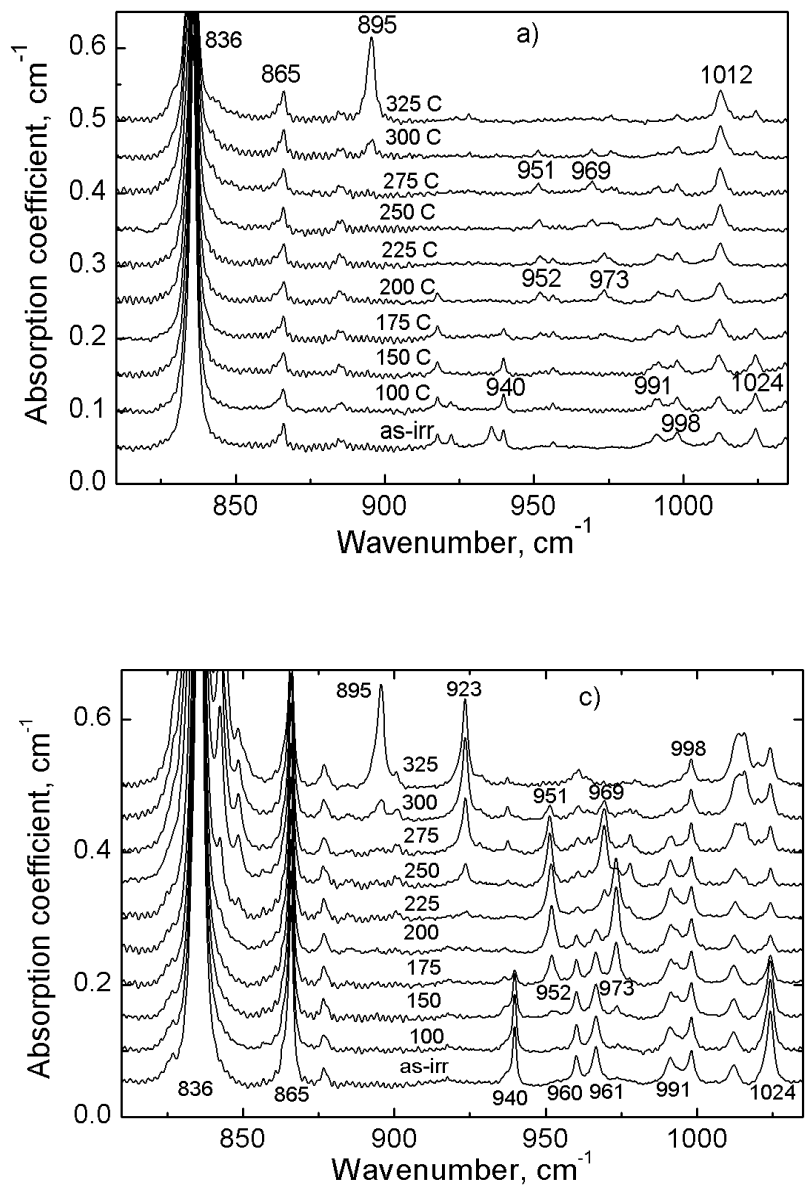



Fig. 4 (a, b, c,). Fragments of absorption spectra measured at $20 \mathrm{~K}$ for $\mathrm{Cz}-\mathrm{Si}$ samples: a) $\left(\left[\mathrm{O}_{\mathrm{i}}\right]=\right.$ $\left.1.15 \times 10^{18},\left[\mathrm{C}_{\mathrm{s}}\right]=5 \times 10^{15},[\mathrm{P}]=7 \times 10^{14} \mathrm{~cm}^{-3}\right)$ irradiated with $10 \mathrm{MeV}$ electrons $\left(F=3 \times 10^{17} \mathrm{~cm}^{-2}\right)$; b) $\left(\left[\mathrm{O}_{\mathrm{i}}\right]=8.3 \times 10^{17},\left[\mathrm{C}_{\mathrm{s}}\right]=7 \times 10^{16},[\mathrm{P}]=1 \times 10^{14} \mathrm{~cm}^{-}\right.$ $\left.{ }^{3}\right)$ irradiated with $10 \mathrm{MeV}$ electrons $\left(F=3 \times 10^{17} \mathrm{~cm}^{-}\right.$ $\left.{ }^{2}\right)$ and $\left.\mathrm{c}\right)\left(\left[\mathrm{O}_{\mathrm{i}}\right]=8.3 \times 10^{17},\left[\mathrm{C}_{\mathrm{s}}\right]=7 \times 10^{16},[\mathrm{P}]=\right.$ $\left.1 \times 10^{14} \mathrm{~cm}^{-3}\right)$ irradiated with $5 \mathrm{MeV}$ neutrons $(F=$ $\left.7.5 \times 10^{16} \mathrm{~cm}^{-2}\right)$. All the samples were annealed for $30 \mathrm{~min}$ at temperatures $\left(\right.$ in ${ }^{\circ} \mathrm{C}$ ) indicated above the spectra.

In Fig. 4a the spectra for a sample with a relatively low carbon content $\left(\sim 5 \times 10^{15} \mathrm{~cm}^{-3}\right)$, which was irradiated with $10 \mathrm{MeV}$ electrons are shown. Figs. $4 \mathrm{~b}$ and $4 \mathrm{c}$ show the spectra for the samples with a higher carbon content $\left(\sim 7 \times 10^{16} \mathrm{~cm}^{-3}\right)$ irradiated with electrons and neutrons. As one can see 
the observed appearance/disappearance of the $\mathrm{C} 4$ related bands are very similar in all the cases and, obviously, should be related to configurational transformations of the $\mathrm{IC}_{\mathrm{i}} \mathrm{O}_{\mathrm{i}}$ defect since the



Fig. 5. The changes in amplitudes of the most intense absorption lines associated with the $\mathrm{IC}_{\mathrm{i}} \mathrm{O}_{\mathrm{i}}, \quad \mathrm{IC}_{\mathrm{i}} \mathrm{O}_{\mathrm{i}}^{*}$, and $\mathrm{IC}_{\mathrm{i}} \mathrm{O}_{\mathrm{i}}^{* *}$ structures [9], normalized to the amplitude of the 1024.2 line after irradiation upon isochronal annealing for the Cz-Si samples: - spectra of which are shown in Fig. 4a, - - see Fig. 4b, o - see Fig. 4c.

ratios of their intensities are approximately the same. The latter is clearly demonstrated in Fig. 5 where the changes upon isochronal annealing in amplitudes of the most intense absorption lines $\left(1024.2,973.2\right.$ and $\left.969.3 \mathrm{~cm}^{-1}\right)$ assigned to the $\mathrm{IC}_{\mathrm{i}} \mathrm{O}_{\mathrm{i}}, \mathrm{IC}_{\mathrm{i}} \mathrm{O}_{\mathrm{i}}{ }^{*}$, and $\mathrm{IC}_{\mathrm{i}} \mathrm{O}_{\mathrm{i}}{ }^{* *}$ structures [9], normalized to the amplitude of the $1024.2 \mathrm{~cm}^{-1}$ band after irradiation, are presented for different samples. Independence of observed changes on carbon content and kind of irradiation (fast electrons or neutrons) provides a strong support to our earlier conclusion on the existence of different configurations of the $\mathrm{C} 4$ defect. At this point it should be noted that the initial $\mathrm{C} 4$ structure (formed upon irradiation) is not a structure with minimum energy. It appears to be a metastable state, and a structure consisting of the $\mathrm{C} 3$ defect with a nearby I atom can be suggested. The most stable configuration corresponds to the $\mathrm{IC}_{\mathrm{I}} \mathrm{O}_{\mathrm{I}}{ }^{* *}$ center. This information and the above presented new experimental data will be helpful if the problem with the $\mathrm{IC}_{\mathrm{i}} \mathrm{O}_{\mathrm{i}}$ structures will be revisited in an $a b$ initio modeling study.

\section{Summary}

We have studied the generation kinetics of the vibrational absorption bands at 998 and $991 \mathrm{~cm}^{-1}$ and found strong additional arguments supporting their previous assignment to the $\mathrm{I}_{2} \mathrm{C}_{\mathrm{i}} \mathrm{O}_{\mathrm{i}}$ and $\mathrm{I}_{3} \mathrm{C}_{\mathrm{i}} \mathrm{O}_{\mathrm{i}}$ complexes. An annealing behaviour of the LVMs related to the $\mathrm{C} 4\left(\mathrm{IC}_{\mathrm{i}} \mathrm{O}_{\mathrm{i}}\right)$ defect has been compared in different Si crystals irradiated with different particles (electrons and/or neutrons). In all the samples studied the bands at 940 and $1024 \mathrm{~cm}^{-1}$ are found to disappear at about $200{ }^{\circ} \mathrm{C}$ while three new LVM bands, at $724 \mathrm{~cm}^{-1}$ (O-related) and at 952 and $973 \mathrm{~cm}^{-1}$ (both C-related) are emerging. Further increase in annealing temperature up to $250-275{ }^{\circ} \mathrm{C}$ results in a transformation of the latter bands into another set of LVM bands at $969 \mathrm{~cm}^{-1}$ (O-related) and at 951 and $977 \mathrm{~cm}^{-1}$ (both C-related). These bands disappear upon annealing in the temperature range $300-325^{\circ} \mathrm{C}$. The ratios of all the bands intensities as well as their transformation rates do not depend on the oxygen and carbon content in the Si samples nor on the kind of irradiation and a dose. These facts confirm the previous conclusion that all the above-mentioned LVMs arise from the $\mathrm{C} 4$ defect being in different configurations $\left(\mathrm{IC}_{\mathrm{i}} \mathrm{O}_{\mathrm{i}}, \mathrm{IC}_{\mathrm{i}} \mathrm{O}_{\mathrm{i}}{ }^{*}\right.$, and $\left.\mathrm{IC}_{\mathrm{i}} \mathrm{O}_{\mathrm{i}}{ }^{* *}\right)$.

\section{Acknowledgments}

We thank Prof. C.A. Londos for a help with irradiation of some Si samples with fast neutrons. Fund for Fundamental Research of the Republic of Belarus (grant F12MC-009) and the Norwegian Research Council (FRINATEK program) are thanked for a partial financial support. 


\section{References}

[1] G. Davies and R.C. Newman, Carbon in monocrystalline silicon, in: T.S. Moss (Ed.), Handbook on Semiconductors, Vol. 3b, Elsevier Science, Amsterdam, 1994, pp. 1557-1635.

[2] F. Shimura (Ed.), Oxygen in Silicon, Semiconductors and Semimetals, Vol. 42, Academic, London, 1994.

[3] J.L. Lindström, T. Hallberg, J. Hermansson, L.I. Murin, V.P. Markevich, M. Kleverman, and B.G. Svensson, Oxygen and carbon clustering in $\mathrm{Cz}-\mathrm{Si}$ during electron irradiation at elevated temperatures, Solid State Phenomena, 69-70 (1999) 297-302.

[4] G. Davies, A.S. Oates, R.C. Newman, R. Woolley, E.C. Lightowlers, M.J. Binns, and J.C. Wilkes, Carbon-related radiation damage centres in Czochralski silicon, J. Phys. C: Solid State Phys. 19 (1986) 841-855.

[5] G. Davies, E.C. Lightowlers, R.C. Newman, and A.S. Oates, A model for radiation damage effects in carbon-doped crystalline silicon, Semicond. Sci. Technol., 2 (1987) 524-532.

[6] J. Coutinho, R. Jones, P.R. Briddon, S. Oberg, L.I. Murin, V.P. Markevich, and J.L. Lindstrom, The interstitial carbon-oxygen center and shallow thermal donors in Si, Phys. Rev. B, 65 (2002) 014109 (1-11).

[7] L.I. Murin, V.P. Markevich, J.L. Lindstrom, M. Kleverman, J. Hermansson, T. Hallberg, and B.G. Svensson, Carbon-oxygen-related complexes in irradiated and heat-treated silicon: IR absorption studies, Solid State Phenomena, 82-84 (2002) 57-62.

[8] G. Davies, S. Hayama, S. Hao, B. Bech Nielsen, J. Coutinho, M. Sanati, S.K. Estreicher, and K.M. Itoh, Host isotope effects on midinfrared optical transitions in silicon, Phys. Rev. B, 71 (2005) 115212 (1-7).

[9] L.I. Murin, J.L. Lindström, G. Davies, V.P. Markevich, Evolution of radiation-induced carbonoxygen-related defects in silicon upon annealing: LVM studies, Nucl. Instrum. Methods Phys. Res. B, 253 (2006) 210-213.

[10] C.A. Londos, M.S. Potsidi, G.D. Antonaras, A. Andrianakis, Isochronal annealing studies of carbon-related defects in irradiated Si, Physica B, 376-377 (2006) 165-168.

[11] M.S. Potsidi, C.A. Londos, The $\mathrm{C}_{\mathrm{i}} \mathrm{C}_{\mathrm{s}}\left(\mathrm{I}_{\mathrm{Si}}\right)$ defect in silicon: An infrared spectroscopy study, J. Appl. Phys. 100 (2006) 033523 (1-4).

[12]D.J. Backlund, S.K. Estreicher, C4 defect and its precursors in Si: First principles theory, Phys. Rev. B, 77 (2008) 205205 (1-8).

[13] J.L. Lindstrom, T. Hallberg, J. Hermansson, L.I. Murin, B.A. Komarov, V.P. Markevich, M. Kleverman, B.G. Svensson, Interaction between self-interstitials and the oxygen dimer in silicon, Physica B: Condensed Matter, 308-310 (2001) 284-289.

[14] A.S. Oates, M.J. Binns, R.C. Newman, J.H. Tucker, J.C. Wilkes, A. Wilkinson, The mechanism of radiation-enhanced diffusion of oxygen in silicon at room temperature, J. Phys. C: Solid State Phys. 17 (1984) 5695-5705.

[15] C.A. Londos, M.S. Potsidi, E. Stakakis, Carbon-related complexes in neutron-irradiated silicon, Physica B, 340-342 (2003) 551-555. 
Gettering and Defect Engineering in Semiconductor Technology XV

10.4028/www.scientific.net/SSP.205-206

Interactions of Self-Interstitials with Interstitial Carbon-Interstitial Oxygen Center in Irradiated Silicon: An Infrared Absorption Study

10.4028/www.scientific.net/SSP.205-206.218 